\title{
Analysis of Renal and Cardiac Outcomes in Male Participants in the Fabry Outcome Survey Starting Agalsidase Alfa Enzyme Replacement Therapy Before and After 18 Years of Age
}

This article was published in the following Dove Press journal:

Drug Design, Development and Therapy

\section{Rossella Parini $\mathbb{D}^{1,2}$ \\ Guillem Pintos-Morell (1D ${ }^{3}$ \\ Julia B Hennermann ${ }^{4}$ \\ Ting-Rong Hsu $\mathbb{D D}^{5}$ \\ Nesrin Karabul ${ }^{6}$ \\ Vasiliki Kalampoki ${ }^{7}$ \\ Andrey Gurevich ${ }^{7}$ \\ Uma Ramaswami (iD ${ }^{8}$ \\ On behalf of the FOS Study Group}

\footnotetext{
'Rare Metabolic Diseases Unit, MBBM Foundation, San Gerardo Hospital, Reference Centre for Hereditary Metabolic Disorders (MetabERN), Monza, Italy; ${ }^{2}$ TIGET Institute, IRCCS San Raffaele Hospital, Milan, Italy; ${ }^{3}$ Division of Rare Diseases, Reference Centre for Hereditary Metabolic Disorders (MetabERN), University Hospital Vall d'Hebron, Autonomous University of Barcelona, Barcelona, Spain; ${ }^{4}$ Villa Metabolica, Department of Pediatric and Adolescent Medicine, University Medical Center, Mainz, Germany; ${ }^{5}$ Department of Pediatrics, Taipei Veterans General Hospital and Faculty of Medicine, National Yang-Ming University, Taipei, Taiwan; ${ }^{6}$ Department of Neuropaediatric and Inborn Metabolic Disorders (Metabolicum Ruhr), University Children's Hospital and Centre for Rare

Diseases, Ruhr University Bochum, Bochum, Germany; ${ }^{7}$ Shire, a Takeda company, Zurich, Switzerland; ${ }^{8}$ Royal Free London NHS Foundation Trust, London, UK
}

Correspondence: Rossella Parini Rare Metabolic Diseases Unit, MBBM Foundation, San Gerardo Hospital, Via Pergolesi 33, Monza 20900, Italy Email Rossella.parini@unimib.it
Purpose: To determine the impact of initiating enzyme replacement therapy (ERT) with agalsidase alfa early in the course of Fabry disease, we evaluated renal and cardiac outcomes for $\leq 10$ years after ERT initiation in males from the Fabry Outcome Survey (FOS).

Patients and Methods: Male patients from FOS were stratified into three cohorts by age at ERT initiation: $\leq 18$ years (cohort 1 ), $>18$ and $\leq 30$ years (cohort 2 ), and $>30$ years (cohort 3 ). Analysis included age at symptom onset, diagnosis, and ERT initiation; ERT duration; FOSMainz Severity Score Index (FOS-MSSI); estimated glomerular filtration rate (eGFR); proteinuria level; and left ventricular mass indexed to height (LVMI). Mixed-effect models estimated renal and cardiac outcomes during follow-up between and within cohorts.

Findings: The analysis included 560 male patients: $151(27.0 \%)$ in cohort $1,155(27.7 \%)$ in cohort 2, and 254 (45.4\%) in cohort 3. Mean \pm SD duration of ERT for cohorts 1, 2, and 3 was 6.3 $\pm 4.3,8.6 \pm 4.9$, and $7.9 \pm 4.9$ years, respectively. Mean \pm SD baseline FOS-MSSI scores increased with age from $9.8 \pm 7.2$ in cohort 1 to $24.7 \pm 11.4$ in cohort 3 . Cohort 3 showed the lowest baseline mean \pm SD value for eGFR $\left(87.1 \pm 29.0 \mathrm{~mL} / \mathrm{min} / 1.73 \mathrm{~m}^{2}\right)$ and highest baseline mean \pm SD values for proteinuria $(801.9 \pm 952.6 \mathrm{mg} /$ day $)$ and LVMI $\left(56.7 \pm 16.0 \mathrm{~g} / \mathrm{m}^{2.7}\right)$ among the three cohorts. Evaluation of mean annual rates of change in eGFR, proteinuria, and LVMI revealed no significant differences in any parameter for cohort 1. For cohort 2, proteinuria and LVMI remained stable, whereas eGFR significantly deteriorated annually $\left(-1.12 \mathrm{~mL} / \mathrm{min} / 1.73 \mathrm{~m}^{2}\right.$; $P<0.001)$. Cohort 3 demonstrated significant annual deteriorations in eGFR $(-2.60 \mathrm{~mL} / \mathrm{min} /$ $\left.1.73 \mathrm{~m}^{2} ; P<0.001\right)$, proteinuria $(+34.10 \mathrm{mg} /$ day; $P<0.001)$, and LVMI $\left(+0.59 \mathrm{~g} / \mathrm{m}^{2.7} ; P=0.001\right)$. Implications: Renal and/or cardiac disease progression appears attenuated in patients starting ERT in childhood or early adulthood versus patients starting ERT in later adulthood. These findings support early ERT initiation in Fabry disease. ClinicalTrials.gov identifier: NCT03289065.

Keywords: agalsidase alfa, Fabry disease, enzyme replacement therapy, Fabry Outcome Survey, estimated glomerular filtration rate, left ventricular hypertrophy

\section{Introduction}

Fabry disease is a progressive, multisystem disease in which nephropathy and cardiomyopathy are frequent and major complications that can lead to premature death. ${ }^{1-4}$ The wide variation in phenotypic presentation among patients with Fabry disease may favor misdiagnosis and delay the correct diagnosis and thus treatment. ${ }^{5,6}$ Enzyme replacement therapy (ERT) has not been shown to prevent further progression if 
initiated during an advanced stage of the disease. ${ }^{7,8}$ Furthermore, evidence-based recommendations promote starting ERT early in the disease course for the greatest therapeutic benefit. ${ }^{9}$

The Fabry Outcome Survey (FOS), sponsored by Shire, a Takeda company (Zurich, Switzerland), is an international disease registry that has been collecting longitudinal data since 2001 on patients with a confirmed diagnosis of Fabry disease. Until 2016, patients either untreated or treated with agalsidase alfa were eligible to participate in the registry. Protocol amendment 4 (dated June 29, 2016) allowed any patients with Fabry disease, regardless of treatment (ie, no treatment or any approved Fabry treatment), to be enrolled. The present analysis included only patients who received ERT with agalsidase alfa. To determine the impact of starting ERT early in the course of Fabry disease, this study evaluated renal and cardiac outcomes up to 10 years after ERT initiation in male patients registered in FOS who started ERT at $\leq 18$ years, $>18$ and $\leq 30$ years, and $>30$ years of age.

\section{Patients and Methods}

This was a retrospective study of data from male patients registered in FOS (data extracted August 2018; ClinicalTrials.gov identifier NCT03289065). FOS was approved by the ethics institutional review boards of participating centers (Supplemental File). All participants or their caregivers gave written informed consent. Patients were stratified into three cohorts according to age at initiation of ERT with agalsidase alfa: $\leq 18$ years of age (cohort 1; child), $>18$ and $\leq 30$ years of age (cohort 2; young adult), and $>30$ years of age (cohort 3; adult). Baseline demographic and clinical characteristics were recorded, including race; age at symptom onset, diagnosis, and ERT initiation; ERT duration; Fabry Outcome Survey-Mainz Severity Score Index (FOSMSSI) results; estimated glomerular filtration rate (eGFR); proteinuria levels; and left ventricular mass indexed to height (LVMI).

The FOS-MSSI is a scoring index used to measure Fabry disease intensity. It consists of general, neurologic, cardiovascular, and renal components, which are combined to calculate the total MSSI score. Scores $<20$ are considered mild, 20-40 moderate, and $>40$ severe. $^{10}$ Clinical judgment about the score must take the age of the patient into account. Renal and cardiac outcomes were analyzed from baseline (defined as within a window of -6 to +3 months around ERT initiation) up to 10 years after ERT initiation. Calculation of eGFR was made using the Counahan-Barratt equation in patients $<18$ years of age and the Chronic Kidney Disease Epidemiology Collaboration equation in patients $\geq 18$ years of age. Decreased eGFR was defined as $<90 \mathrm{~mL} / \mathrm{min} / 1.73 \mathrm{~m}^{2}$ and was used as a measure of reduced renal function. ${ }^{11}$ Proteinuria was defined as a protein excretion rate of $\geq 150 \mathrm{mg} /$ day. ${ }^{12}$ Increased LVMI was considered as values $>50 \mathrm{~g} / \mathrm{m}^{2.7}$ and was used as a measure of left ventricular hypertrophy $(\mathrm{LVH}){ }^{13}$

\section{Statistical Analysis}

The baseline demographic and clinical characteristics were compared among the three study cohorts using analysis of variance (ANOVA), which constituted the most appropriate statistical method for comparing means because it assesses the relative size of variance when more than two groups are being tested. The null hypothesis for an ANOVA is that there is no significant difference among the groups, whereas the alternative hypothesis assumes that there is at least one significant difference among the groups. An assumption of normality was assessed in the current study with the Shapiro-Wilk test, and the Tukey's method was used for the post-hoc test.

Mixed-effects linear regression analysis was used to estimate mean values for renal and cardiac outcomes for the overall follow-up period within and between cohorts and, subsequently,mean annual changes within each cohort. An unstructured covariance (patient level) with the fixed effect of age at ERT initiation (cohorts 1-3, as listed earlier) and the random effect of patients and time were implemented in the models. Restricted maximum likelihood estimation was used to fit the models. $P$ values were calculated using the Wald test. To be included in the mixed-effects linear regression analysis, patients were required to have (1) a minimum of 3 years of receiving ERT,(2) nonmissing baseline data,(3) a minimum of 3 years of postbaseline data,(4) a minimum of three measurements, and (5) no renal dialysis and/or transplant prior to ERT initiation. For patients with renal dialysis and/or transplant at any time over the course of followup,data were deleted after the timing of renal dialysis and/ or transplant. Data up to a maximum of 10 years after ERT initiation were used.

The level of statistical significance was set at 0.05. All analyses were performed using SAS (SAS software version 9.4). 


\section{Results}

\section{Baseline Characteristics}

A total of 560 male patients registered in FOS received ERT with agalsidase alfa and were included in this study. There were $151(27.0 \%)$ patients in cohort 1, $155(27.7 \%)$ patients in cohort 2, and 254 (45.4\%) patients in cohort 3 (Table 1). Median (range) age at symptom onset was lower in cohort 1 (7.5 [0.0-16.0] years) than in cohort $2(8.0$ [0.0-17.0] years) or cohort 3 (9.0 [0.0-17.0] years; $P=$ 0.017). Age at diagnosis was higher in each successive age group and ranged from a median (range) of $11.0(0.0$ 18.0) years in cohort 1 to $31.0(0.0-69.0)$ years in cohort 3. Mean \pm SD duration of ERT for cohorts 1, 2, and 3 was $6.3 \pm 4.3,8.6 \pm 4.9$, and $7.9 \pm 4.9$ years, respectively. Mean \pm SD FOS-MSSI scores at baseline increased with age in each successive cohort, from $9.8 \pm 7.2$ in cohort 1 to $24.7 \pm 11.4$ in cohort 3. Mean \pm SD eGFR for cohorts 1 and 2 was $113.8 \pm 26.9$ and $118.3 \pm 20.0 \mathrm{~mL} / \mathrm{min} / 1.73 \mathrm{~m}^{2}$, respectively. Mean \pm SD proteinuria for cohorts 1 and 2 was $120.6 \pm 239.3$ and $295.2 \pm 476.6 \mathrm{mg} /$ day, respectively. Additionally, LVMI for cohorts 1 and 2 was $36.7 \pm 7.9$ and $40.4 \pm 11.0 \mathrm{~g} / \mathrm{m}^{2.7}$, respectively. Cohort 3 , comprising the oldest patients, showed the lowest baseline mean \pm SD value for eGFR $\left(87.1 \pm 29.0 \mathrm{~mL} / \mathrm{min} / 1.73 \mathrm{~m}^{2}\right)$ and highest baseline mean $\pm \mathrm{SD}$ values for proteinuria (801.9 \pm $952.6 \mathrm{mg} /$ day $)$ and LVMI $\left(56.7 \pm 16.0 \mathrm{~g} / \mathrm{m}^{2.7}\right)$ among the three cohorts.

Totals of $15(17.0 \% ; \mathrm{n}=88), 11(10.1 \% ; \mathrm{n}=109)$, and 70 $(46.7 \% ; \mathrm{n}=150)$ patients in cohorts 1,2 , and 3 , respectively, had pathological eGFR $\left(<90 \mathrm{~mL} / \mathrm{min} / 1.73 \mathrm{~m}^{2}\right)$ at baseline; whereas $13(21.0 \% ; \mathrm{n}=62), 35(47.9 \% ; \mathrm{n}=73)$, and 94 $(81.0 \% ; \mathrm{n}=116)$ patients in cohorts 1,2 , and 3 , respectively, had pathological proteinuria $(\geq 150 \mathrm{mg} /$ day $)$ at baseline. Totals of $3(6.8 \% ; \mathrm{n}=44), 9(16.1 \% ; \mathrm{n}=56)$, and 48 $(64.9 \% ; n=74)$ patients in cohorts 1,2 , and 3 , respectively, had pathological LVMI $\left(>50 \mathrm{~g} / \mathrm{m}^{2.7}\right)$ at baseline.

\section{Follow-up for ERT}

In a comparison of the cohorts, the overall mean values for eGFR and proteinuria did not significantly differ between patients in cohorts 1 and 2 during the follow-up period for ERT, whereas some significant differences were found for LVMI (Table 2). However, a comparison of patients in cohorts 1 and 3 showed significant differences in overall mean values for eGFR (117.9 vs $79.9 \mathrm{~mL} / \mathrm{min} / 1.73 \mathrm{~m}^{2}$, respectively), proteinuria (210.7 vs $819.5 \mathrm{mg} /$ day, respectively), and LVMI (33.6 vs $55.5 \mathrm{~g} / \mathrm{m}^{2.7}$, respectively;
$P<0.001$ for each). A comparison of patients in cohorts 2 and 3 also showed significant differences in overall mean values for eGFR (114.1 vs $79.9 \mathrm{~mL} / \mathrm{min} / 1.73 \mathrm{~m}^{2}$, respectively), proteinuria (395.5 vs $819.5 \mathrm{mg} /$ day, respectively), and LVMI (40.0 vs $55.5 \mathrm{~g} / \mathrm{m}^{2.7}$, respectively; $P<0.001$ for each).

For patients in cohort 1, no significant annual changes in eGFR, proteinuria, or LVMI were observed throughout the follow-up period (Table 3). For patients in cohort 2, although proteinuria and LVMI remained stable, eGFR showed a significant annual decline over the follow-up period (slope, $-1.12 \mathrm{~mL} / \mathrm{min} / 1.73 \mathrm{~m}^{2}$ [95\% confidence interval $\{\mathrm{CI}\},-1.77$ to -0.47$]$; $P<0.001$ ). For patients in cohort 3 , a significant annual deterioration over the follow-up period was shown for eGFR (slope, $-2.60 \mathrm{~mL} / \mathrm{min} / 1.73 \mathrm{~m}^{2}$ [95\% CI, -3.16 to -2.04$] ; P<0.001$ ), proteinuria (slope, $+34.10 \mathrm{mg} /$ day [95\% CI, 18.48-49.71]; $P<0.001$ ), and LVMI (slope, $+0.59 \mathrm{~g} / \mathrm{m}^{2.7}$ [95\% CI, 0.23-0.95]; $P=0.001$ ). Figures 1-3 illustrate the estimated annual rates of change over the follow-up period for each cohort by parameter, showing that the patients in cohort 3 had worsening rates of change during follow-up for eGFR, proteinuria, and LVMI in comparison with cohorts 1 and 2 .

\section{Discussion}

The three different age cohorts included in this analysis effectively represent populations at different stages of disease progression, as expected and as reflected by the FOSMSSI scores and clinical symptoms.

We observed that individuals with systemic Fabry disease treated with ERT in childhood or early adulthood (cohorts 1 and 2) exhibited a stable eGFR slope or a slight decline in eGFR slope, respectively, and no changes in proteinuria slope during the course of the follow-up period. The slopes for eGFR and proteinuria were much more pronounced in cohort 3 compared to cohorts 1 and 2 .

Breunig et al reported a worse outcome and greater likelihood of reaching renal and cardiovascular end points in male and female patients treated with agalsidase alfa who had more severe renal involvement at baseline. ${ }^{14}$ Germain et al also reported an increased likelihood of renal disease progression in patients treated with agalsidase beta who already had higher renal impairment at baseline, compared with patients who did not. ${ }^{15}$ A 10year outcome study that included male and female patients 
Table I Demographic and Clinical Characteristics at Baseline in Male Patients with Fabry Disease According to Age at ERT Initiation

\begin{tabular}{|c|c|c|c|c|c|}
\hline Characteristics & $\begin{array}{l}\text { Cohort I } \\
\text { ( } \leq 18 \text { Years) } \\
n=15 \mid\end{array}$ & $\begin{array}{l}\text { Cohort } 2 \\
(>18 \text { and } \leq 30 \text { Years) } \\
n=155\end{array}$ & $\begin{array}{l}\text { Cohort } 3 \\
(>30 \text { Years) } \\
n=254\end{array}$ & $\begin{array}{l}\text { Total } \\
N=\mathbf{5 6 0}\end{array}$ & $P$ value $^{a}$ \\
\hline $\begin{array}{l}\text { Race } \\
\text { n } \\
\text { White, n (\%) } \\
\text { Black/African American, n (\%) } \\
\text { Asian, n (\%) } \\
\text { Other, n (\%) }\end{array}$ & $\begin{array}{l}148 \\
95(64.2) \\
1(0.7) \\
49(33.1) \\
3(2.0)\end{array}$ & $\begin{array}{l}155 \\
132(85.2) \\
0(0.0) \\
16(10.3) \\
7(4.5)\end{array}$ & $\begin{array}{l}252 \\
213(84.5) \\
0(0.0) \\
34(13.5) \\
5(2.0)\end{array}$ & $\begin{array}{l}555 \\
440(79.3) \\
1(0.2) \\
99(17.8) \\
15(2.7)\end{array}$ & $<0.001$ \\
\hline $\begin{array}{l}\text { Age at symptom onset, y } \\
\text { n } \\
\text { Mean (SD) } \\
\text { Median (QI, Q3) } \\
\text { Range }\end{array}$ & $\begin{array}{l}112 \\
7.6(3.7) \\
7.5(5.0,10.0) \\
0.0-16.0\end{array}$ & $\begin{array}{l}155 \\
8.5(4.4) \\
8.0(5.0,12.0) \\
0.0-17.0\end{array}$ & $\begin{array}{l}254 \\
8.9(3.7) \\
9.0(6.0,12.0) \\
0.0-17.0\end{array}$ & $\begin{array}{l}521 \\
8.5(3.9) \\
8.0(6.0,11.0) \\
0.0-17.0\end{array}$ & 0.017 \\
\hline $\begin{array}{l}\text { Age at diagnosis, y } \\
\text { n } \\
\text { Mean (SD) } \\
\text { Median (QI, Q3) } \\
\text { Range }\end{array}$ & $\begin{array}{l}146 \\
10.4(4.6) \\
11.0(8.0,14.0) \\
0.0-18.0\end{array}$ & $\begin{array}{l}153 \\
17.8(6.7) \\
18.0(14.0,23.0) \\
0.0-28.0\end{array}$ & $\begin{array}{l}252 \\
29.3(13.9) \\
31.0(17.0,39.0) \\
0.0-69.0\end{array}$ & $\begin{array}{l}551 \\
21.1(13.0) \\
17.0(11.0,30.0) \\
0.0-69.0\end{array}$ & $<0.001$ \\
\hline $\begin{array}{l}\text { Age at ERT initiation, y } \\
\mathrm{n} \\
\text { Mean (SD) } \\
\text { Median (QI, Q3) } \\
\text { Range }\end{array}$ & $\begin{array}{l}15 \mid \\
13.0(3.8) \\
13.7(10.9,16.1) \\
2.5-18.0\end{array}$ & $\begin{array}{l}155 \\
24.1(3.4) \\
24.5(21.2,26.9) \\
18.0-29.9\end{array}$ & $\begin{array}{l}254 \\
41.6(8.2) \\
40.3(34.9,48.2) \\
30.0-69.2\end{array}$ & $\begin{array}{l}560 \\
29.1(13.7) \\
27.7(17.4,39.4) \\
2.5-69.2\end{array}$ & $<0.001$ \\
\hline $\begin{array}{l}\text { ERT duration, y } \\
\qquad \mathrm{n} \\
\text { Mean (SD) } \\
\text { Median (QI, Q3) } \\
\text { Range }\end{array}$ & $\begin{array}{l}|5| \\
6.3(4.3) \\
5.5(2.9,9.4) \\
0.0-16.3\end{array}$ & $\begin{array}{l}155 \\
8.6(4.9) \\
8.4(4.0,12.4) \\
0.0-17.1\end{array}$ & $\begin{array}{l}254 \\
7.9(4.9) \\
7.0(3.8,12.2) \\
0.0-18.1\end{array}$ & $\begin{array}{l}560 \\
7.6(4.8) \\
7.1(3.6,11.7) \\
0.0-18.1\end{array}$ & $<0.001$ \\
\hline $\begin{array}{l}\text { FOS-MSSI } \\
\text { n } \\
\text { Mean (SD) } \\
\text { Median (QI, Q3) } \\
\text { Range }\end{array}$ & $\begin{array}{l}145 \\
9.8(7.2) \\
8.0(5.0,12.5) \\
0.0-35.0\end{array}$ & $\begin{array}{l}152 \\
15.1(8.5) \\
13.5(8.3,21.5) \\
0.0-39.5\end{array}$ & $\begin{array}{l}250 \\
24.7(11.4) \\
23.5(16.5,33.5) \\
1.0-52.5\end{array}$ & $\begin{array}{l}547 \\
18.1(11.6) \\
16.0(8.5,25.5) \\
0.0-52.5\end{array}$ & $<0.001$ \\
\hline $\begin{array}{l}\text { Used at least one ACE inhibitor } \\
\text { n } \\
\text { Yes, n (\%) } \\
\text { No, n (\%) }\end{array}$ & $\begin{array}{l}|5| \\
20(13.2) \\
131(86.8)\end{array}$ & $\begin{array}{l}155 \\
50(32.3) \\
105(67.7)\end{array}$ & $\begin{array}{l}254 \\
145(57.1) \\
109(42.9)\end{array}$ & $\begin{array}{l}560 \\
215(38.4) \\
345(61.6)\end{array}$ & \\
\hline $\begin{array}{l}\text { Systolic blood pressure, } \mathrm{mmHg} \\
\text { n } \\
\text { Mean (SD) } \\
\text { Median (QI, Q3) } \\
\text { Range }\end{array}$ & $\begin{array}{l}91 \\
111.6(14.3) \\
110.0(104.0,122.0) \\
74.0-143.0\end{array}$ & $\begin{array}{l}90 \\
120.1(13.0) \\
120.0(110.0,129.0) \\
97.0-155.0\end{array}$ & $\begin{array}{l}155 \\
125.2(16.4) \\
124.0(115.0,134.0) \\
87.0-174.0\end{array}$ & $\begin{array}{l}336 \\
120.1(16.0) \\
120.0(110.0,130.0) \\
74.0-174.0\end{array}$ & $<0.001$ \\
\hline $\begin{array}{l}\text { Diastolic blood pressure, } \mathrm{mmHg} \\
\mathrm{n} \\
\text { Mean (SD) } \\
\text { Median (QI, Q3) } \\
\text { Range }\end{array}$ & $\begin{array}{l}91 \\
63.8(10.8) \\
63.0(59.0,70.0) \\
40.0-100.0\end{array}$ & $\begin{array}{l}90 \\
71.4(9.6) \\
70.0(64.0,80.0) \\
47.0-98.0\end{array}$ & $\begin{array}{l}154 \\
75.3(11.5) \\
74.0(70.0,80.0) \\
50.0-110.0\end{array}$ & $\begin{array}{l}335 \\
71.1(11.8) \\
70.0(63.0,80.0) \\
40.0-110.0\end{array}$ & $<0.001$ \\
\hline
\end{tabular}


Table I (Continued).

\begin{tabular}{|c|c|c|c|c|c|}
\hline Characteristics & $\begin{array}{l}\text { Cohort I } \\
\text { ( } \leq 18 \text { Years) } \\
n=15 \mid\end{array}$ & $\begin{array}{l}\text { Cohort } 2 \\
(>18 \text { and } \leq 30 \text { Years) } \\
n=155\end{array}$ & $\begin{array}{l}\text { Cohort } 3 \\
\text { (>30 Years) } \\
n=254\end{array}$ & $\begin{array}{l}\text { Total } \\
N=\mathbf{5 6 0}\end{array}$ & $P$ value $^{a}$ \\
\hline $\begin{array}{l}\text { eGFR, } \mathrm{mL} / \mathrm{min} / \mathrm{l} .73 \mathrm{~m}^{2 \mathrm{~b}, \mathrm{c}} \\
\mathrm{n} \\
\text { Mean (SD) } \\
\text { Median (QI, Q3) } \\
\text { Range }\end{array}$ & $\begin{array}{l}88 \\
113.8(26.9) \\
112.4(96.5,133.2) \\
48.9-17 \mid .1\end{array}$ & $\begin{array}{l}109 \\
118.3(20.0) \\
120.9(109.9,129.6) \\
35.6-163.4\end{array}$ & $\begin{array}{l}150 \\
87.1(29.0) \\
93.1(62.7,110.7) \\
23.2-145.2\end{array}$ & $\begin{array}{l}347 \\
103.7(29.7) \\
109.1(85.7,123.3) \\
23.2-171.1\end{array}$ & $<0.001$ \\
\hline $\begin{array}{l}\text { Proteinuria, mg/day } \\
\text { n } \\
\text { Mean (SD) } \\
\text { Median (QI, Q3) } \\
\text { Range }\end{array}$ & $\begin{array}{l}62 \\
120.6(239.3) \\
88.6(27.0,142.4) \\
0.0-1870.0\end{array}$ & $\begin{array}{l}73 \\
295.2(476.6) \\
140.0(70.0,220.0) \\
0.0-2450.0\end{array}$ & $\begin{array}{l}116 \\
801.9(952.6) \\
440.0(200.0,1002.5) \\
0.0-4900.0\end{array}$ & $\begin{array}{l}251 \\
486.3(766.1) \\
180.0(96.0,540.0) \\
0.0-4900.0\end{array}$ & $<0.001$ \\
\hline $\begin{array}{l}\text { LVMI, g/m.7e } \\
\text { n } \\
\text { Mean (SD) } \\
\text { Median (QI, Q3) } \\
\text { Range }\end{array}$ & $\begin{array}{l}44 \\
36.7(7.9) \\
34.9(32.3,38.4) \\
22.0-61.0\end{array}$ & $\begin{array}{l}56 \\
40.4(11.0) \\
37.9(33.1,45.8) \\
19.2-76.9\end{array}$ & $\begin{array}{l}74 \\
56.7(16.0) \\
55.6(45.8,67.9) \\
25.8-96.6\end{array}$ & $\begin{array}{l}174 \\
46.4(15.6) \\
43.2(34.3,55.5) \\
19.2-96.6\end{array}$ & $<0.001$ \\
\hline
\end{tabular}

Notes: a $P$ value, comparing the mean values across the three cohorts, derived from analysis of variance; beGR values were restricted to between $>15$ and $\leq 180 \mathrm{~mL} / \mathrm{min} /$ $1.73 \mathrm{~m}^{2}$, values outside this range were considered as missing; 'eGFR was calculated using the Counahan-Barratt equation in patients <18 years of age and the Chronic Kidney Disease Epidemiology Collaboration equation in patients $\geq 18$ years of age; ${ }^{d}$ proteinuria values were restricted to between $\geq 0$ and $\leq 5000 \mathrm{mg} /$ day, values outside this

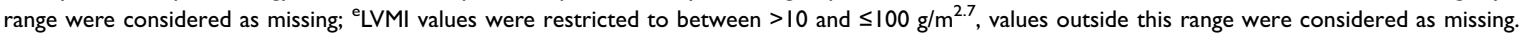

Abbreviations: ACE, angiotensin-converting enzyme; Cl, confidence interval; eGFR, estimated glomerular filtration rate; ERT, enzyme replacement therapy; FOS-MSSI, Fabry Outcome Survey-Mainz Severity Score Index; LVMI, left ventricular mass indexed to height; Q, quartile; SD, standard deviation.

receiving agalsidase beta ERT found greater benefit from initiating ERT in younger patients with less severe renal disease than in older patients with more severe renal disease, in whom disease progression was observed. ${ }^{7}$ In contrast, Beck et al reported a benefit of agalsidase alfa ERT even in male patients with the lowest eGFR values at baseline, as indicated by a slower decline in renal disease progression compared with untreated patients. ${ }^{16}$

Owing to the lack of a control group of untreated patients, we cannot say with certainty to what extent the favorable slopes in cohorts 1 and 2 may depend on treatment. However, the effect of ERT on the natural progression of the disease is easily recognized if we compare the aforementioned findings with those of untreated patients. In a 2017 article by Arends et al, the natural history of Fabry disease was studied in 596 patients from three European centers; 129 patients with available data were male and had classical Fabry disease. ${ }^{17}$ The slope of linear regression reported for eGFR in these patients shows a decline starting from 20 years of age; in comparison, the slopes of cohorts 1 and 2 observed in the present study were fairly stable over the course of the follow-up period. Our data analysis also indicated a numerically statistically significant decline found with cohort 2 (eGFR slope -1.12), which is consistent with the natural yearly decline of eGFR found in healthy individuals $(-0.82 \pm 0.22$ for those aged 20-30 years and $-1.15 \pm 0.12 \mathrm{~mL} / \mathrm{min} /$ $1.73 \mathrm{~m}^{2}$ per year for those aged $>50$ years $) .{ }^{19}$ The slope for cohort 3, however, was more similar to that shown by Arends et al for patients of approximately the same age. ${ }^{17}$ Schiffmann et al reported the natural progression of chronic kidney disease in untreated adult patients with Fabry disease and showed that male patients with eGFR $\geq 60 \mathrm{~mL} / \mathrm{min} / 1.73 \mathrm{~m}^{2}$ and a mean age of 27.3 years had a rate of eGFR decline of $2.93 \mathrm{~mL} / \mathrm{min} / 1.73 \mathrm{~m}^{2}$ per year. $^{18}$ This group of male patients was of approximately the same age as this study's cohort 2, in which patients showed a much slower annual decline of eGFR with a slope of -1.12 per year. Schiffman et al also reported that in a group of patients who were of comparable age to this study's cohort 3 and had progressed to end-stage renal disease, the eGFR slope was -3.85 ; this contrasts with the eGFR slope of -2.60 observed in cohort 3 in the present study. Schiffman et al also reported in a subgroup of untreated patients with higher proteinuria at baseline a decline in eGFR of -6.9 . 


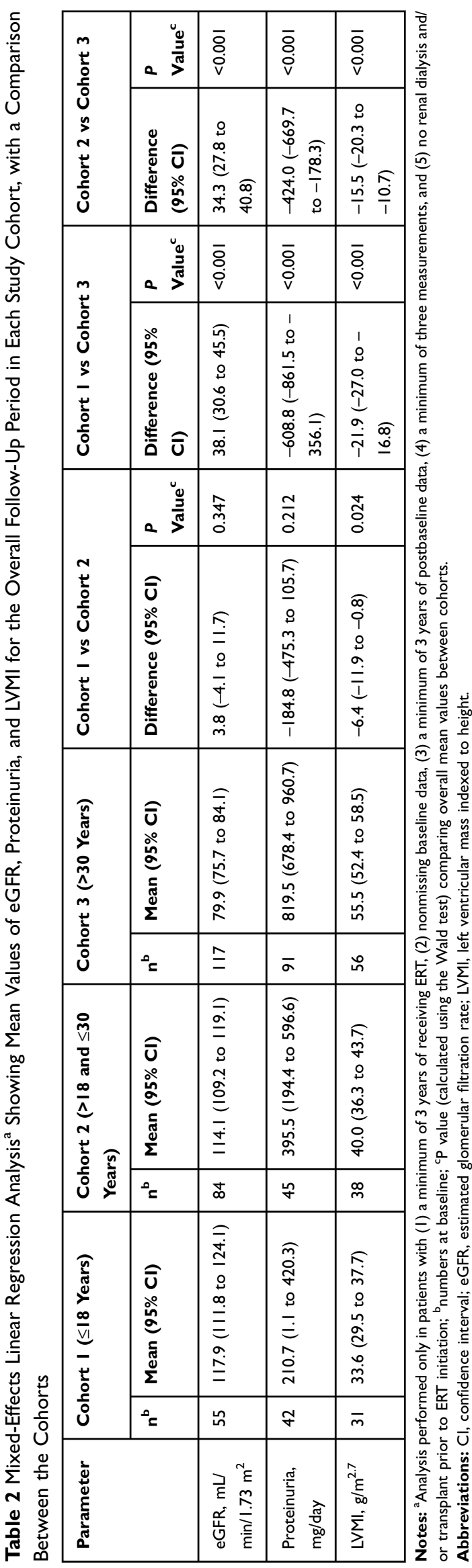

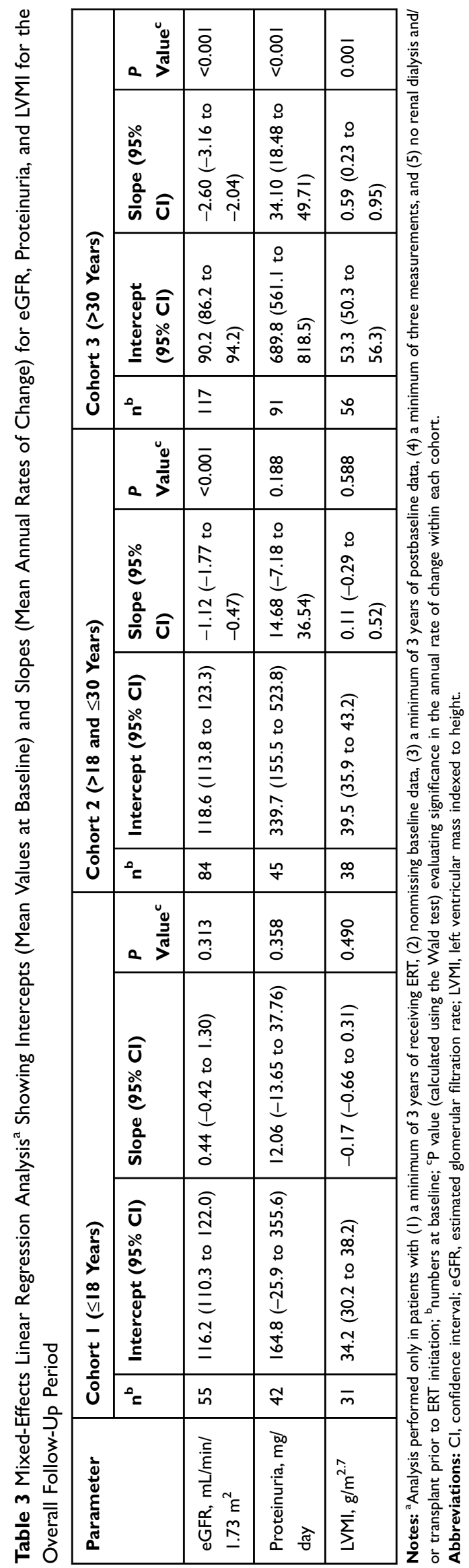




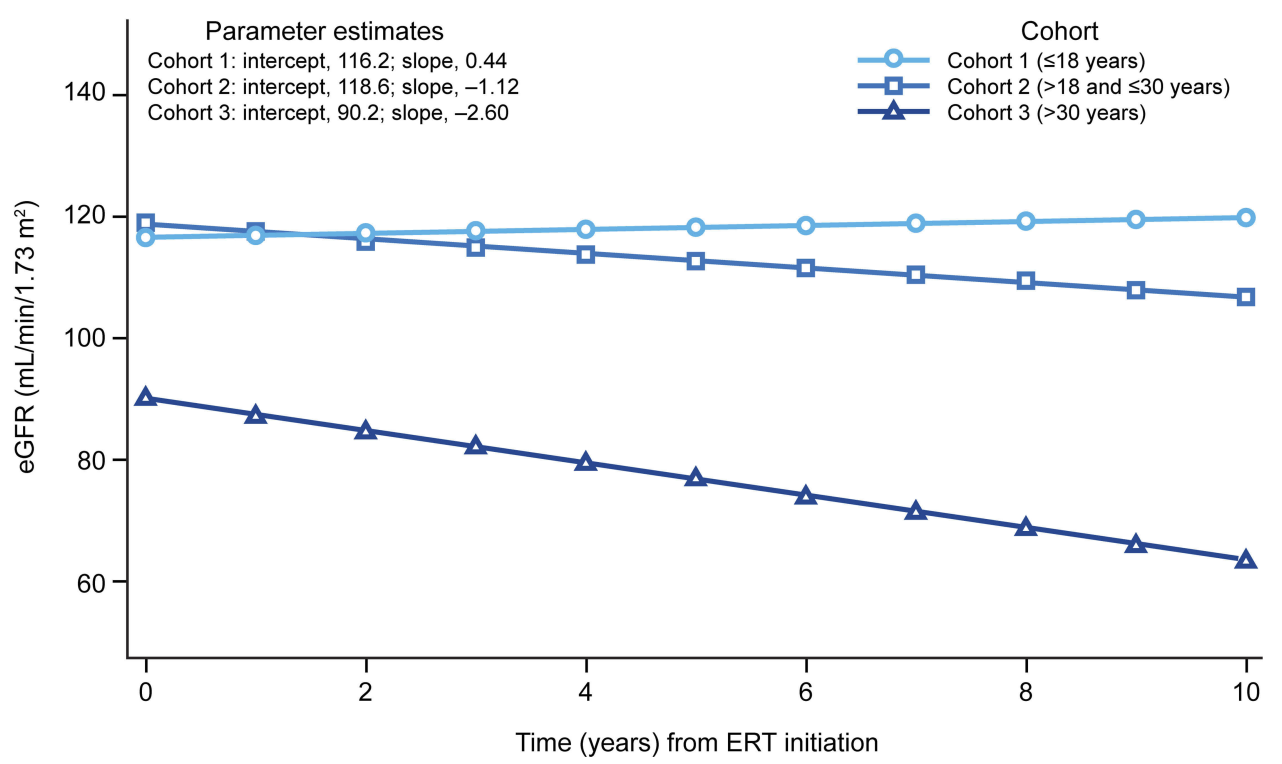

Figure I Estimated regression lines for estimated glomerular filtration rate (eGFR) values over time according to age at enzyme replacement therapy (ERT) initiation.

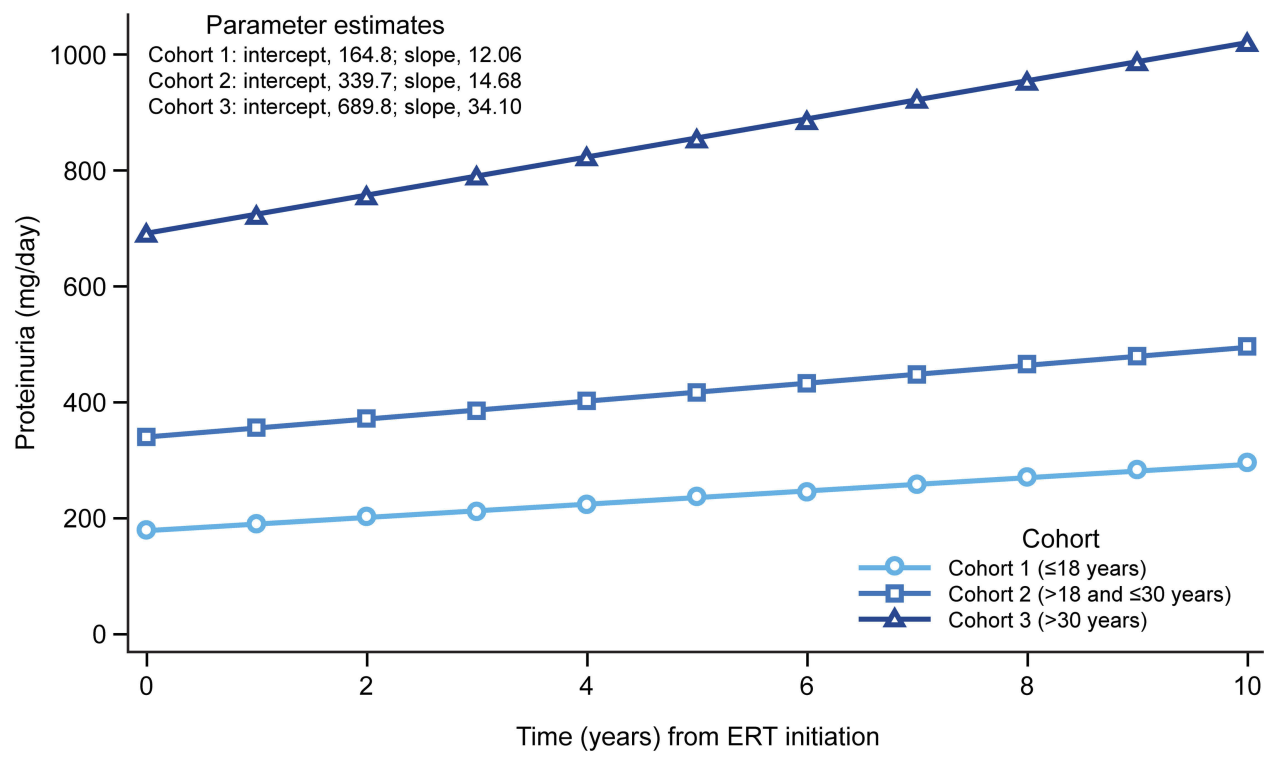

Figure 2 Estimated regression lines for proteinuria values over time according to age at enzyme replacement therapy (ERT) initiation.

The current analysis found that in patients with the most severe renal disease, the highest proteinuria was observed at baseline and was consistently high throughout the follow-up period. In agreement with a previously reported age at onset of proteinuria of $34 \pm 10$ years, ${ }^{1}$ significant increases in annual rates of proteinuria were found only in patients in cohort 3, whereas in patients who started ERT in childhood or early adulthood, no annual changes of proteinuria were identified. Kampmann et al reported a significant increase in urinary protein levels after 10 years in male patients who had proteinuria before agalsidase alfa ERT initiation, whereas no significant changes were seen in patients without baseline proteinuria. $^{20}$

LVMI did not progress in cohorts 1 and 2 over the course of the follow-up period. Although in patients younger than 30 years of age the prevalence of LVMI is known to be low, ${ }^{21}$ it is possible that ERT contributed to stabilizing LVMI in cohorts 1 and 2 . In cohort 3 , there was evidence of significant deterioration of LVMI over the course of the follow-up period. 


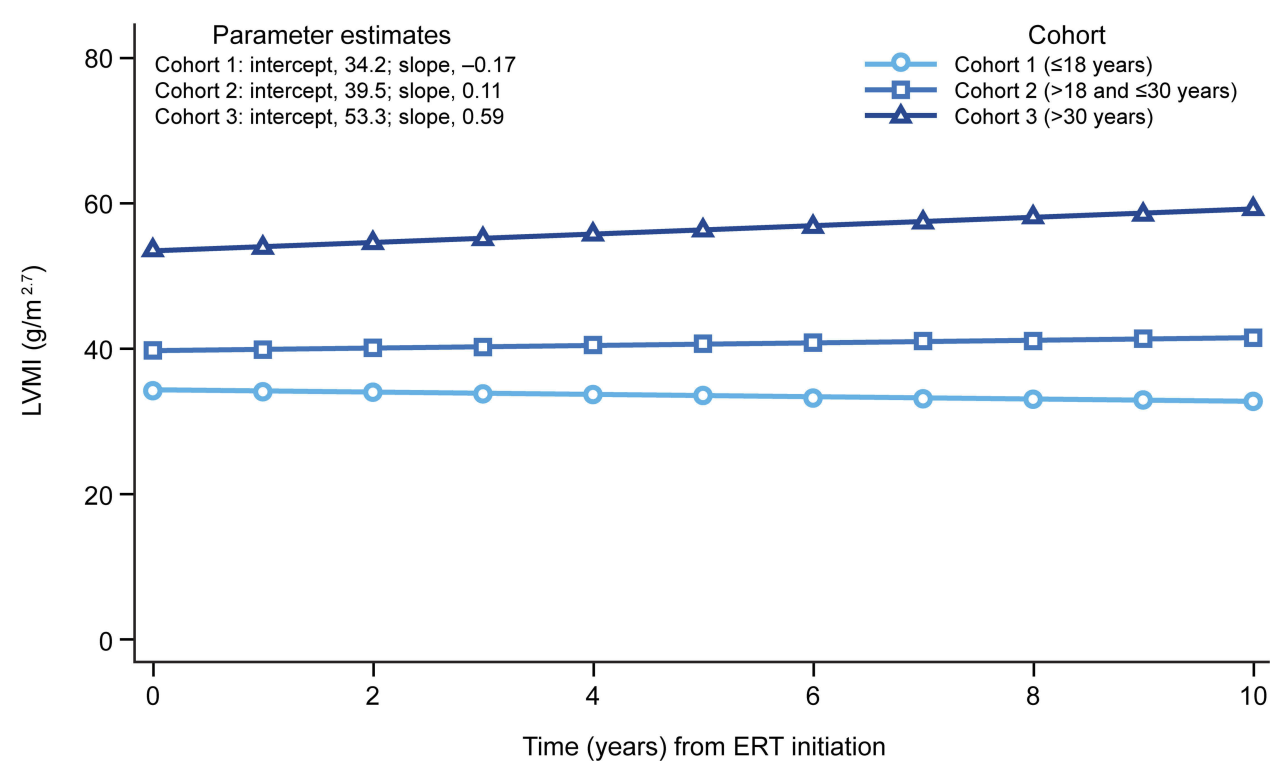

Figure 3 Estimated regression lines for left ventricular mass indexed to height (LVMI) values over time according to age at enzyme replacement therapy (ERT) initiation.

Again, owing to the lack of an untreated control group, it is difficult to determine the effect of ERT. However, the slope representing the linear regression curve of LVMI in untreated patients shown by Arends et $\mathrm{al}^{17}$ appears to be very different from that shown for cohorts 1 and 2 of this analysis in patients of approximately the same age. Age at onset of LVH in untreated patients has been reported to be in the fourth to fifth decade for male patients and the sixth decade for female patients; ${ }^{2,4}$ however, $\mathrm{Wu}$ et al reported LVH even in female patients $<20$ years of age. ${ }^{22}$ Weidemann et al demonstrated progression of cardiac and renal disease in patients with advanced Fabry disease, despite treatment with agalsidase alfa or beta. ${ }^{8}$ Germain et al reported that initiating agalsidase beta ERT in male patients $\geq 40$ years of age was associated with greater LVH progression compared with male patients $\leq 30$ years of age. ${ }^{23}$ Kampmann et al found a significant reduction of LVMI in male patients with LVH at baseline after 1 year of ERT with agalsidase alfa, which was sustained over 10 years. ${ }^{20}$

There are limitations to these analyses to be considered. FOS is an observational registry and lacks a control group for intraregistry data comparisons. Because patients are not randomly enrolled in disease registries, selection bias in favor of those individuals with worse disease may have been introduced to the data evaluated in this study. Patient numbers in the three cohorts were relatively small, and some data were unavailable for inclusion in the analyses, as is often the case in rare disease registries. All findings should be interpreted with caution owing to the large amount of missing values, especially in cohort 3 . Because the analysis period was limited to a maximum of 10 years after ERT initiation, some male patients in cohort 1 were still young and at an age where the effect of the disease on the heart and kidney is likely to be mild, even if untreated. Lastly, although further analysis of study participants according to phenotype/mutation would be informative, it was not practically feasible due to a limited availability of genetic data.

The current analysis shows that ERT is associated with attenuation of progressive Fabry disease-related renal and cardiac disease in patients who started treatment between 18 and 30 years of age (cohort 2). Our data reasonably suggest that this effect could be even more pronounced in cohort 1 (patients starting ERT before 18 years of age), but, owing to the well-known evolution of Fabry disease in the first 3 decades of life and to the lack of a control group, we cannot assert the finding. Older patients are generally expected to have a worse prognosis in Fabry disease. It is thus true that cohort 3 included older patients compared to cohort 1 and cohort 2 and may be at a more advanced disease stage, thus reinforcing the idea of early starting treatment to achieve a slowing of disease progression.

\section{Conclusion}

In a small cohort of patients with full sets of longitudinal data, the current analysis shows that initiating ERT in childhood and young adulthood was associated with greater attenuation of progressive Fabry diseaserelated renal and cardiac disease compared with initiating ERT in later adulthood. These results add to and 
support the growing body of evidence indicating that greater clinical benefits may be obtained the earlier ERT is initiated.

\section{Abbreviations}

ACE, angiotensin-converting enzyme; ANOVA, analysis of variance; CI, confidence interval; eGFR, estimated glomerular filtration rate; ERT, enzyme replacement therapy; FOS, Fabry Outcome Survey; FOS-MSSI, Fabry Outcome Survey-Mainz Severity Score Index; LVH, left ventricular hypertrophy; LVMI, left ventricular mass indexed to height; $Q$, quartile.

\section{Data Sharing Statement}

The datasets, including redacted study protocol, redacted statistical analysis plan, and individual participants' data behind the results reported in this article, will be available three months after the submission of a request to https:// www.shiretrials.com/en/our-commitment-to-transparency /data-sharing-with-researchers by researchers who provide a methodologically sound proposal, after de-identification, in compliance with applicable privacy laws, data protection and requirements for consent and anonymization.

\section{Ethics Approval and Consent Statement}

FOS was approved by the ethics institutional review boards of participating centers (Supplemental File). Further, this registry was compliant with relevant global and local regulations and best practices. Good Pharmacoepidemiological Practice, Good Research for Comparative Effectiveness principles, and the relevant principles of the International Conference on Harmonisation Good Clinical Practice (ICH GCP) guidelines (ICH E6) were followed as appropriate for an observational registry and consistent with the Declaration of Helsinki. All participants or their caregivers gave written informed consent.

\section{Acknowledgments}

Dr Uma Ramaswami is the senior author of this study. The authors would like to thank Jaco Botha (Shire International $\mathrm{GmbH}$, a Takeda company) for his contribution to the initial statistical analyses, which was supported by Shire, a Takeda company. Under the direction of the authors, Latoya M. Mitchell, PhD, CMPP, and Tina Rose, MSc, both of Excel Medical Affairs, provided writing assistance for this manuscript. Editorial assistance in the form of formatting, proofreading, copy editing, and fact-checking also was provided by Excel Medical Affairs. Shire International GmbH, a Takeda company, provided funding to Excel Medical Affairs for support in writing and editing this manuscript.

\section{Author Contributions}

All authors contributed to data analysis, drafting or revising the article, gave final approval of the version to be published, and agree to be accountable for all aspects of the work.

\section{Funding}

The Fabry Outcome Survey is sponsored by Shire Human Genetic Therapies, Inc., a Takeda company. Shire International $\mathrm{GmbH}$, a Takeda company, funded this study, was involved in study design, the collection, analysis, and interpretation of data, the writing of the report, and the decision to submit the article for publication.

\section{Disclosure}

Dr Parini reports personal fees and clinical trial participation from Shire, a Takeda company, and personal fees from BioMarin, Chiesi, Sanofi Genzyme, and Ultragenyx, outside the submitted work. Dr Pintos-Morrell reports personal fees from Alexion, Amicus, BioMarin, Kyowa-Kirin, Sanofi Genzyme, and Shire, a Takeda company, outside the submitted work. Dr Hennermann reports grants and personal fees from Shire, a Takeda company, and personal fees from Amicus, outside the submitted work. Dr Karabul reports grants and personal fees from Shire, a Takeda company, grants and personal fees from Sanofi Genzyme, and personal fees from BioMarin, outside the submitted work. Ms Kalampoki is an employee of and reports stock ownership from Shire, a Takeda company, during the conduct of the study. Dr Gurevich was an employee of Shire, a Takeda company, during the conduct of the study. Dr Ramaswami reports personal fees and clinical trial participation from Amicus, clinical trial participation from Protalix; grants, personal fees, and clinical trial participation from Sanofi Genzyme; grants, personal fees, and clinical trial participation from Shire, a Takeda company; and personal fees from Actelion, Idorsi, and Chiesi, outside the submitted work. The authors report no other conflicts of interest in this work.

\section{References}

1. Branton MH, Schiffmann R, Sabnis SG, et al. Natural history of Fabry renal disease: influence of alpha-galactosidase A activity and genetic mutations on clinical course. Medicine (Baltimore). 2002;81 (2):122-138. doi:10.1097/00005792-200203000-00003

2. Mehta A, Ricci R, Widmer U, et al. Fabry disease defined: baseline clinical manifestations of 366 patients in the Fabry Outcome Survey. Eur J Clin Invest. 2004;34(3):236-242. doi:10.1111/j.1365-2362.2004.01309.x 
3. Kampmann C, Baehner F, Whybra C, et al. Cardiac manifestations of Anderson-Fabry disease in heterozygous females. J Am Coll Cardiol. 2002;40(9):1668-1674. doi:10.1016/s0735-1097(02)02380-x

4. Linhart A, Kampmann C, Zamorano JL, et al. Cardiac manifestations of Anderson-Fabry disease: results from the international Fabry Outcome Survey. Eur Heart J. 2007;28(10):1228-1235. doi:10.1093/eurheartj/ehm153

5. Reisin R, Perrin A, García-Pavía P. Time delays in the diagnosis and treatment of Fabry disease. Int J Clin Pract. 2017;71(1). doi:10.1111/ ijcp. 12914

6. Desnick RJ, Brady R, Barranger J, et al. Fabry disease, an under-recognized multisystemic disorder: expert recommendations for diagnosis, management, and enzyme replacement therapy. Ann Intern Med. 2003;138(4):338-346. doi:10.7326/0003-4819-1384-200302180-00014

7. Germain DP, Charrow J, Desnick RJ, et al. Ten-year outcome of enzyme replacement therapy with agalsidase beta in patients with Fabry disease. J Med Genet. 2015;52(5):353-358. doi:10.1136/jmedgenet-2014-102797

8. Weidemann F, Niemann M, Störk S, et al. Long-term outcome of enzyme-replacement therapy in advanced Fabry disease: evidence for disease progression towards serious complications. J Intern Med. 2013;274(4):331-341. doi:10.1111/joim.12077

9. Biegstraaten M, Arngrimsson R, Barbey F, et al. Recommendations for initiation and cessation of enzyme replacement therapy in patients with Fabry disease: the European Fabry Working Group consensus document. Orphanet J Rare Dis. 2015;10:36. doi:10.1186/s13023015-0253-6

10. Whybra C, Kampmann C, Krummenauer F, et al. The Mainz Severity Score Index: a new instrument for quantifying the Anderson-Fabry disease phenotype, and the response of patients to enzyme replacement therapy. Clin Genet. 2004;65(4):299-307. doi:10.1111/j.13990004.2004.00219.x

11. Kidney Disease Improving Global Outcomes (KDIGO). KDIGO 2012 clinical practice guideline for the evaluation and management of chronic kidney disease. Kidney Int Suppl. 2013;3(1):1-150.

12. Walker HK, Hall WD, Hurst JW. Clinical Methods: The History, Physical, and Laboratory Examinations. 3rd ed. Boston, MD: Butterworths; 1990.

13. de Simone G, Devereux RB, Daniels SR, Koren MJ, Meyer RA, Laragh JH. Effect of growth on variability of left ventricular mass: assessment of allometric signals in adults and children and their capacity to predict cardiovascular risk. J Am Coll Cardiol. 1995;25 (5):1056-1062. doi:10.1016/0735-1097(94)00540-7
14. Breunig F, Weidemann F, Strotmann J, Knoll A, Wanner C. Clinical benefit of enzyme replacement therapy in Fabry disease. Kidney Int. 2006;69(7):1216-1221. doi:10.1038/sj.ki.5000208

15. Germain DP, Waldek S, Banikazemi M, et al. Sustained, long-term renal stabilization after 54 months of agalsidase beta therapy in patients with Fabry disease. $J$ Am Soc Nephrol. 2007;18 (5):1547-1557. doi:10.1681/ASN.2006080816

16. Beck M, Hughes D, Kampmann C, et al. Long-term effectiveness of agalsidase alfa enzyme replacement in Fabry disease: a Fabry Outcome Survey analysis. Mol Genet Metab Rep. 2015;3:21-27. doi:10.1016/j.ymgmr.2015.02.002

17. Arends M, Wanner C, Hughes D, et al. Characterization of classical and nonclassical Fabry disease: a multicenter study. J Am Soc Nephrol. 2017;28(5):1631-1641. doi:10.1681/ASN.2016090964

18. Schiffmann R, Warnock DG, Banikazemi M, et al. Fabry disease: progression of nephropathy, and prevalence of cardiac and cerebrovascular events before enzyme replacement therapy. Nephrol Dial Transplant. 2009;24(7):2102-2111. doi:10.1093/ndt/gfp031

19. Cohen E, Nardi Y, Krause I, et al. A longitudinal assessment of the natural rate of decline in renal function with age. J Nephrol. 2014;27 (6):635-641. doi:10.1007/s40620-014-0077-9

20. Kampmann C, Perrin A, Beck M. Effectiveness of agalsidase alfa enzyme replacement in Fabry disease: cardiac outcomes after 10 years' treatment. Orphanet J Rare Dis. 2015;10:125. doi:10.1186/ s13023-015-0338-2

21. Kampmann C, Linhart A, Baehner F, et al. Onset and progression of the Anderson-Fabry disease related cardiomyopathy. Int J Cardiol. 2008;130(3):367-373. doi:10.1016/j.ijcard.2008.03.007

22. Wu JC, Ho CY, Skali H, et al. Cardiovascular manifestations of Fabry disease: relationships between left ventricular hypertrophy, disease severity, and alpha-galactosidase A activity. Eur Heart J. 2010;31 (9):1088-1097. doi:10.1093/eurheartj/ehp588

23. Germain DP, Weidemann F, Abiose A, et al. Analysis of left ventricular mass in untreated men and in men treated with agalsidase- $\beta$ : data from the Fabry Registry. Genet Med. 2013;15(12):958-965. doi:10.1038/gim.2013.53

\section{Publish your work in this journal}

Drug Design, Development and Therapy is an international, peerreviewed open-access journal that spans the spectrum of drug design and development through to clinical applications. Clinical outcomes, patient safety, and programs for the development and effective, safe, and sustained use of medicines are a feature of the journal, which has also been accepted for indexing on PubMed Central. The manuscript management system is completely online and includes a very quick and fair peer-review system, which is all easy to use. Visit http://www. dovepress.com/testimonials.php to read real quotes from published authors. 